\title{
Amoeboid Locomotion of Acanthamoeba castellanii with Special Reference to Cell-Substratum Interactions
}

\author{
By T. M. PRESTON* AND C. A. KING \\ Department of Zoology, University College, London WCIE 6BT, UK
}

(Received 13 April 1984)

\begin{abstract}
The amoeboid locomotion of Acanthamoeba castellanii has been studied by observation of individual cells moving on a planar glass substratum. Cell-substratum interactions involved in traction have been observed by reflexion interference microscopy. A variable part of the ventral surface of $\boldsymbol{A}$. castellanii formed a protean platform, the 'associated contact', from which filopodia were subtended; these established stable, focal adhesions (approximately $0.4 \mu \mathrm{m}$ diameter) on the substratum beneath. Surprisingly, acanthopodia, a prominent feature of this protozoon, did not play an obvious role in traction. The dimensions of the cell-substratum gap in the associated contact could be modulated by the concentration of ambient electrolyte. Dilution of electrolyte from $50 \mathrm{~mm}-\mathrm{KCl}$ to $2 \mathrm{~mm}$ resulted in (i) an increase in the cell-substratum gap, (ii) a marked decrease in cell motility, (iii) reduced cell adhesion to glass.
\end{abstract}

\section{INTRODUCTION}

In order to reach an understanding of the mechanism of amoeboid motility it is necessary to define (i) the essential features of locomotory behaviour including interactions with the substratum, (ii) the nature and distribution of the cytoskeleton and cytomuscular components, and (iii) the biochemical properties of these components and their ability to interact with each other. With regard to this third aspect, more information has come from the study of the ubiquitous protozoon Acanthamoeba (Pollard et al., 1982) than from any other cell. On the other hand, there has to date been no analysis of the locomotory behaviour of this soil amoeba with reference to substratum interactions. Since Acanthamoeba can be an opportunistic pathogen in man, causing chronic granulomatous amoebic encephalitis, keratitis, optic neuritis or macular disease (reviewed by Martinez, 1983), an understanding of its locomotory mechanism may assume a wider significance than hitherto realized. Such infections occur not by the ingestion of a cyst, as in the case of the dysentery pathogen Entamoeba histolytica, but by the invasion of human tissues by the motility of Acanthamoeba trophozoites.

Our investigations on another common soil amoeba, Naegleria gruberi, have enabled us to build up probably the most complete picture so far of the cell-substratum behaviour during crawling locomotion of any eukaryotic cell. By using a combination of light and electron microscope techniques we have defined those morphological features of the ventral surface of Naegleria amoebae responsible for traction (Preston \& King, 1972a, b). The influence of environmental parameters such as substratum properties (Preston \& O'Dell, 1980; King et al., 1981, 1983a), electrolyte concentration (King et al., 1979) and temperature (King et al., 1983b), have been studied and the consequences for locomotory performance and strength of attachment to a substratum considered (King et al., 1982). Unfortunately, unlike the situation with Acanthamoeba, there is as yet no information on the biochemistry of the putative force generation machinery in Naegleria. Therefore, we decided to apply the methods which had proved so successful with Naegleria to define the locomotory behaviour of Acanthamoeba. 


\section{METHODS}

Cell culture. Acanthamoeba castellanii stocks 1501/1 a (Neff strain) and 1534/3 (Singh strain) were obtained from the Culture Centre of Algae \& Protozoa, Cambridge, UK, and grown axenically as monolayers in tissue culture flasks at $25^{\circ} \mathrm{C}$ in a liquid medium (Korn, 1963). Cultures were harvested in the exponential growth phase. Firstly the unattached cells were removed by decanting the growth medium and then a wash with $50 \mathrm{~mm}-\mathrm{NaCl}$ was carried out. Adhesive cells were then removed into $50 \mathrm{mM}-\mathrm{NaCl}$ by vigorous shaking and concentrated by gentle centrifugation. After a repeat of this cycle, the amoebae were resuspended to a concentration of about $5 \times$ $10^{6}$ cells $\mathrm{ml}^{-1}$ in $50 \mathrm{~mm}-\mathrm{NaCl}$.

Measurement of speed of locomotion and relative strength of adhesion. An observation chamber was made by taking a standard glass microscope slide $(75 \times 25 \times 1.2 \mathrm{~mm})$, placing two glass spacers $(1.2 \mathrm{~mm}$ thick $)$ about $2 \mathrm{~cm}$ apart on the surface and then putting a rectangular coverslip on the top. The cell suspension in $50 \mathrm{~mm}-\mathrm{NaCl}$ could then be introduced into the space between coverslip and glass slide using a Pasteur pipette. The solution in the chambers could be replaced as necessary. Individual amoebae in the chamber were selected at random and their locomotory path followed for $1 \mathrm{~min}$ using a camera lucida as described previously (King et al., 1979). Speed of movement was calculated both for cells attached to the top coverslip (inverted) and those confined to the bottom glass substratum (non-inverted). In order to keep the tonicity of solutions constant, sucrose was added to adjust the final osmolarity of all experimental solutions to $0 \cdot 1$ osmol $1^{-1}$. The observation chambers were also used to determine relative strengths of adhesion by the ability of amoebae to remain attached to the top coverslip while the solution in the chamber was altered by perfusion. In experiments in which the majority of the cells remained adherent following introduction of the test solution, cell adhesion was scored as ' + '. In those experiments where $90 \%$ or more of the cells were lost from the top coverslip on changing the medium, a ' - ' score was given (see Table 1). In another series of experiments the relative strength of Acanthamoeba adhesion to glass under different electrolyte conditions was investigated with a glass capillary apparatus previously used with Naegleria gruberi (King et al., 1982). This enabled us to compare the adhesive performance of these two soil amoebae under identical experimental conditions.

Phase contrast and reflexion interference microscopy. These techniques were carried out essentially as described by Preston \& King (1978b).

\section{RESULTS}

\section{Phase contrast microscopy of motile amoebae}

The shape of motile amoebae can vary considerably from a broad, crab-like form, in which the width of the advancing edge is equal to or greater than the length, to a more elongate form in which the length $(25-40 \mu \mathrm{m})$ is greater than the width $(10-20 \mu \mathrm{m})$. It is the latter form which will be described.

The general morphology of an actively locomoting cell can be seen from Figs 1 and 2 . At the front, which is usually broader than the rear, there is a conspicuous hyaline zone from which cytoplasmic granules are excluded. The hyaline zone is extensive and was calculated from Fig. 1 to be about $22 \%$ of the cell profile area as viewed from above. At the leading edge of Acanthamoeba short, spine-like projections, the acanthopodia, are produced. Locomotion is marked by the gradual extension forward of a lobopodium over the substratum. This lobopodium varies in its width and from time to time one side of its leading edge may become dominant causing a lateral diversion from the previous locomotory pathway of the amoeba.

The presumptive acanthopodia are first detected as refractile dots which develop into the radiating, rigid processes which are clearly visible on the lateral margins of the hyaline zone. The acanthopodia are also present on the dorsal surface but here they are far less obvious and require critical focussing to be seen by phase contrast microscopy, although their presence is readily revealed by scanning electron microscopy.

The lateral acanthopodia remain stationary with respect to fixed laboratory co-ordinates (Fig. 1) and thus appear to move backwards with respect to the advancing lobopodium of the amoeba. Time lapse cinematography indicates that the dorsal acanthopodia also behave in this fashion although they are remote from the planar substratum. The life expectancy of a single acanthopodium is variable, but (see Fig. 1) it is frequently less than $20 \mathrm{~s}$. The breakdown of an acanthopodium is shown in a time sequence in Fig. 2. Usually this breakdown occurs at the interface between the hyaline zone of the cell and the granular endoplasm. Dissolution of the acanthopodia may occur in either of two ways. The junction with the cortex may plasticize and 


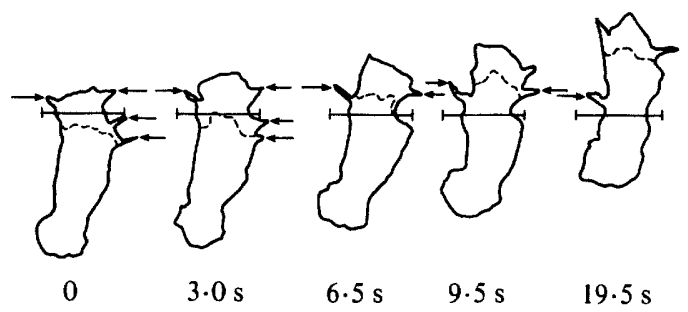

Fig. 1. Sequence of line drawings obtained from a video recording using transmitted light microscopy of a single amoeba locomoting on a glass substratum in $50 \mathrm{mM}-\mathrm{NaCl}$. The bar $(10 \mu \mathrm{m})$ acts as a fixed spatial marker and amoeboid motility can be related to this with respect to time. The broken line represents the boundary between the clear anterior hyaline zone and the posterior granular endoplasm. The arrows denote acanthopodia initially present at time zero (only one of these remained at 19.5 s).

the projection swing back and fuse laterally with the cell surface. Alternatively, the cytoplasmic matrix of the acanthopodium may be withdrawn leaving a wispy, membraneous vestige of the former process.

\section{Reflexion interference microscopy}

This technique, using incident illumination of the specimen, provides the only direct method of monitoring the dynamic morphology of interactions between the underside of a living, motile cell and its substratum. Simultaneous use of conventional transmitted light microscopy enables the interference pattern obtained from a given cell to be related to its overt motile behaviour.

Under conditions of very low electrolyte (specific conductance less than $6 \mu \mathrm{S}$ ) part of the ventral face of Acanthamoeba located in the mid-region of the cell can be seen by reflexion interference microscopy to form a platform which generates a white, zero order interference pattern in tungsten illumination. This area is variable in form and represents the closest approach made by the bulk of the cell to the substratum. By analogy with $N$. gruberi we call this the 'associated contact'. Micro-extensions subtended from the associated contact link it with the substratum via small, punctate, focal contacts (Fig. $3 a$ ). These stable adhesions are about $0.4 \mu \mathrm{m}$ in diameter and generate a black interference image. In the associated contact there is a marked polarity with regard to the formation and breakdown of focal adhesions. They are seen to originate in the associated contact at its anterior margin and remain fixed with regard to external co-ordinates until, with the progression of the amoeba, they come to reside in the posterior part of the cell; here the focal contacts may detach from the substratum. De-adhesion appears to be clean for there is no obvious trace of previous focal attachments remaining on the glass surface.

It is important to stress that the associated contact and focal contacts could not be discerned in Acanthamoeba by conventional light microscopy. Reflexion interference microscopy of this protozoon also revealed that anterior to the associated contact and coincident with the leading edge of the advancing lobopodium there is an additional interference pattern consisting of varying numbers of highly mobile islands of unstable contact (Fig. $3 a$ ). When $50 \mathrm{mM}-\mathrm{NaCl}$ was perfused gently into the chamber the associated contact changed from white through grey to black - the focal contacts were then no longer resolvable (Fig. $3 b$ ). This change could be reversed fully on adequate dilution of the electrolyte. Whereas in very low electrolyte the associated contact and the anterior islands were always discrete, in $50 \mathrm{~mm}-\mathrm{NaCl}$ they often became continuous. Occasionally some lateral acanthopodia made transient contact with the substratum by their tips; however, such interactions were not a prerequisite for the progression of Acanthamoeba across a planar glass surface.

The contact interactions of Acanthamoeba with a glass substratum generate a highly protean interference pattern (Fig. 4). For the particular cell shown in Fig. 4 replacement of $50 \mathrm{~mm}-\mathrm{NaCl}$ by the perfusion of $100 \mathrm{~mm}$-sucrose led to an $80 \%$ reduction in the contact area/cell profile area ratio accompanied by an overall lightening of the reflection interference image. The amoeba 

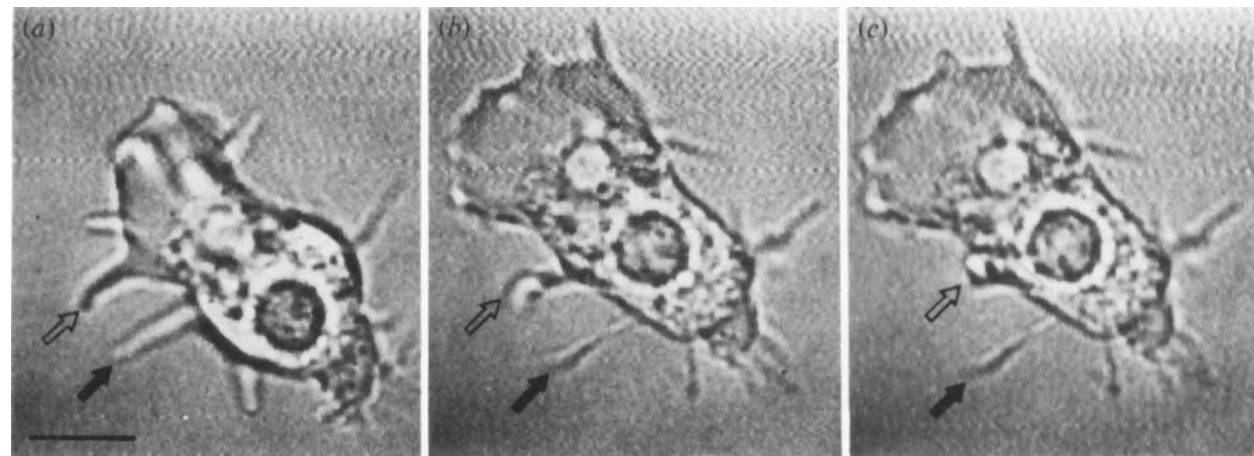

Fig. 2. Sequence of photomicrographs of an individual amoeba locomoting on a glass substratum in $50 \mathrm{mM}-\mathrm{NaCl}$. Two specific acanthopodia in this series are indicated by arrows. Bar marker, $10 \mu \mathrm{m}$. (a) Time zero; (b) $9 \mathrm{~s} ;(c) 10 \mathrm{~s}$.
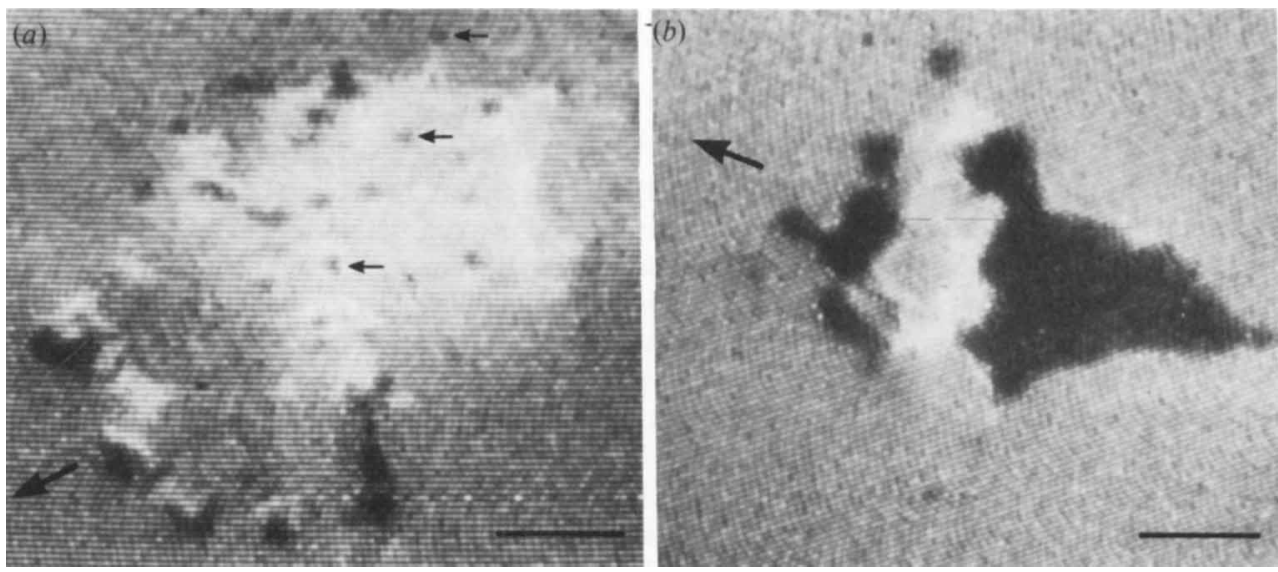

Fig. 3. (a) Reflexion interference micrograph of the ventral surface of an amoeba in low ionic strength medium on a glass substratum. The small arrows indicate some of the punctate focal contacts which are generally found within the white associated contact area. The topmost arrow indicates a focal contact, just before de-adhesion, linked to the ventral surface of the cell by a filopodium. (b) Reflexion interference micrograph of the ventral surface of an amoeba in $50 \mathrm{mM}-\mathrm{NaCl}$ on a glass substratum. The large arrows at the anterior of the cells indicate the direction of movement. Bar markers, $5 \mu \mathrm{m}$.

soon lost contact with the coverslip and was carried away by the gentle perfusion stream. We found that a lowering of the electrolyte concentration below critical values produced this general effect. However, a minority of cells could maintain their attachment to the glass substratum even in distilled water (Fig. $3 a$ ).

\section{Effects of ambient electrolyte concentration on the motility and adhesion to glass of Acanthamoeba}

When amoebae in $50 \mathrm{~mm}-\mathrm{NaCl}$ were settled onto the presumptive top coverslip of a chamber and then inverted, they were able to adhere well to the glass (Table 1). No significant difference in locomotion rate was found between cells moving on the top coverslip (i.e. inverted) or those already attached to the bottom microscope slide (i.e. non-inverted).

When the $50 \mathrm{mM}-\mathrm{NaCl}$ in the chamber was replaced by 20 or $10 \mathrm{~mm}-\mathrm{NaCl}$ no significant difference in either cell adhesion or speed of movement was found. However, when the ambient electrolyte was reduced to $2 \mathrm{mM}-\mathrm{NaCl}$, there was an abrupt decline in the ability of amoebae to remain attached to the top coverslip and almost all of them fell off. Although a few cells remained on the bottom of the glass slide their capacity for translocation was negligible. 

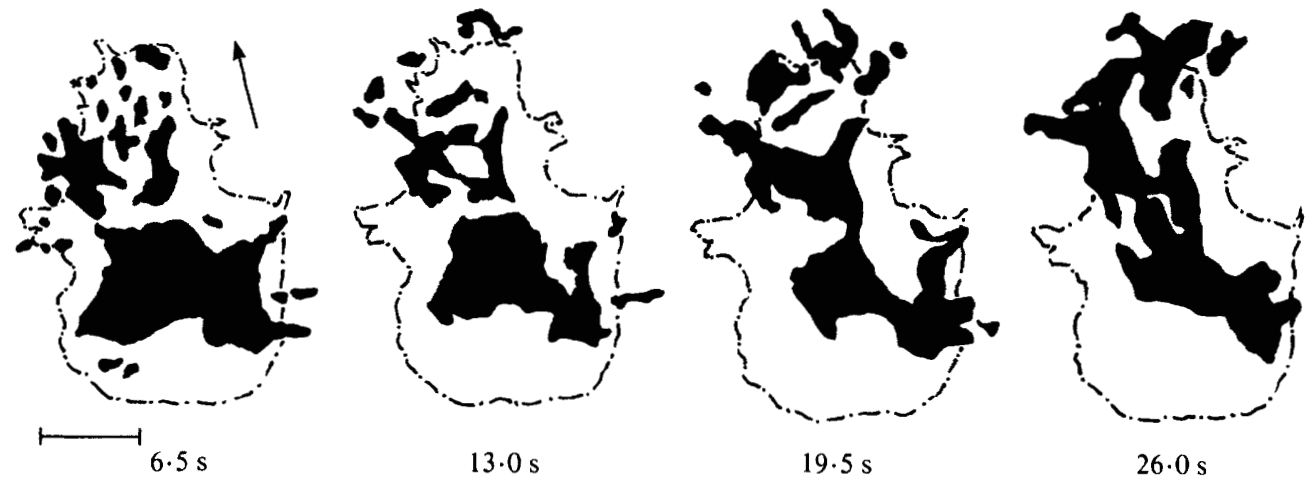

Fig. 4. Sequence of line drawings obtained from a video recording using reflexion interference microscopy of cell-substratum contact changes obtained from the ventral surface of a single amoeba moving on a glass coverslip in $50 \mathrm{mM}-\mathrm{NaCl}$. The broken line represents the cell profile obtained using transmitted light at time zero and serves as a fixed spatial marker to which the changes in cellsubstratum contacts (black areas) can be related. The arrow denotes the direction of movement. Bar marker, $10 \mu \mathrm{m}$.

Table 1. Effect of ionic composition of the medium on the adhesion of amoebae to the top coverslip and motility of the cells on the top coverslip (inverted) and the bottom glass substratum (non-inverted)

\begin{tabular}{|c|c|c|c|c|}
\hline \multicolumn{2}{|c|}{ Medium } & \multirow{3}{*}{$\begin{array}{l}\text { Cell adhesion } \\
\text { to top } \\
\text { coverslip }\end{array}$} & \multirow{2}{*}{\multicolumn{2}{|c|}{ Speed of movement $\left(\mu \mathrm{m} \mathrm{s}^{-1}\right)^{*}$}} \\
\hline \multirow[b]{2}{*}{ Salt } & \multirow{2}{*}{$\begin{array}{c}\underset{\text { Concn }}{(\mathrm{mM})} \\
\end{array}$} & & & \\
\hline & & & Inverted & Non-inverted \\
\hline \multirow[t]{4}{*}{$\mathrm{NaCl}$} & 50 & + & $0.099 \pm 0.073$ & $0.085 \pm 0.031$ \\
\hline & 20 & + & $0.185 \pm 0.068$ & $0.100 \pm 0.052$ \\
\hline & 10 & + & $0 \cdot 155 \pm 0 \cdot 100$ & $0.094 \pm 0.036$ \\
\hline & 2 & - & $\mathrm{NA}$ & 0.0 \\
\hline $\mathbf{K C l}$ & 2 & - & NA & 0.0 \\
\hline$\left(\mathrm{NH}_{4}\right)_{2} \mathrm{SO}_{4}$ & 1 & - & NA & 0.0 \\
\hline \multirow[t]{3}{*}{$\mathrm{CaCl}_{2}$} & 1 & + & ND & $0.161 \pm 0.076$ \\
\hline & 0.5 & + & ND & $0.101 \pm 0.033$ \\
\hline & 0.1 & - & NA & 0.0 \\
\hline
\end{tabular}

* Values are $\pm \mathrm{SD}, n=20$. ND, Not done; NA, not applicable.

Essentially similar results were obtained with replacement of $50 \mathrm{mM}-\mathrm{NaCl}$ by $2 \mathrm{mM}-\mathrm{KCl}$ or $1 \mathrm{mM}-\left(\mathrm{NH}_{4}\right)_{2} \mathrm{SO}_{4}$. Replacement of $50 \mathrm{mM}-\mathrm{NaCl}$ by $1 \mathrm{mM}-\mathrm{CaCl}_{2}$ (ionic strength equal to that of $\left.1 \mathrm{mM}-\left(\mathrm{NH}_{4}\right)_{2} \mathrm{SO}_{4}\right)$ or $0.5 \mathrm{mM}-\mathrm{CaCl}_{2}$ maintained both cell-substratum adhesion and amoeboid locomotion. A further dilution of this $\mathrm{CaCl}_{2}$ concentration to $0.1 \mathrm{mM}$ led to a loss of cell attachment and locomotion.

In a further experiment a polylysine treated glass coverslip was prepared and amoebae in $100 \mathrm{~mm}$-sucrose were placed on this coated surface. Although the specific conductance of the medium was very low (equivalent to distilled water) the amoebae were firmly attached to the coverslip and achieved speeds of movement of $0.06 \pm 0.021$ (mean $\pm \mathrm{SD}$ ) $\mu \mathrm{m} \mathrm{s}^{-1}$ across it.

Using the capillary tube method (King et al., 1982) Acanthamoeba cells were allowed to settle in $50 \mathrm{mM}-\mathrm{NaCl}$ on the capillary wall, and then subjected to perfusion with various test solutions. When $50 \mathrm{~mm}$-, $10 \mathrm{mM}-, 2 \mathrm{~mm}$ - and $1 \mathrm{mM}-\mathrm{NaCl}$ were used as test electrolytes, $84,82,33$ and $31 \%$, respectively, of the cells remained adherent. In comparable experiments using Naegleria amoebae initially settling in $10 \mathrm{~mm}-\mathrm{NaCl}$ (King et al., 1982), when $10 \mathrm{mM}$ - and $1 \mathrm{~mm}-\mathrm{NaCl}$ and distilled water were used, 86,72 and $44 \%$, respectively, of the cells remained adherent. 


\section{DISCUSSION}

Despite considerable differences in the morphology and rates of locomotion of Acanthamoeba castellanii and Naegleria gruberi (Preston \& King, 1978 a,b) the use of reflexion interference microscopy has shown that their basic features of cell-substratum interaction are similar. That is, a variable part of the cell undersurface forms a platform, the associated contact, from which are subtended filopodia that establish stable focal adhesions to the substratum. These focal contacts are of similar size $(0.4 \mu \mathrm{m}$ diameter) in both amoebae and show a common cycle of formation anteriorly and breakdown posteriorly in an advancing cell. Acanthamoeba is more complex than Naegleria in expressing two morphologically distinct types of surface projections filopodia, which are formed on the ventral surface of the amoeba and generate the focal contacts, and acanthopodia which are confined to the lateral and dorsal regions of the cell. Since motility can occur without acanthopodia contacting the substratum, they can play no obligatory role in the generation of traction of a planar surface.

The modulation of the cell-substratum gap by the ambient electrolyte concentration has profound effects on the speed of movement of Acanthamoeba and parallels our previous observations on Naegleria (King et al., 1979). Although for a given salt concentration (e.g. $10 \mathrm{~mm}-\mathrm{NaCl}$ ) Acanthamoeba moves considerably more slowly than Naegleria, there is the common trend that mobility is reduced as the electrolyte level falls.

This decrease in translocation of Acanthamoeba with lowered electrolyte concentration was paralleled by a decreasing ability of the amoeba to remain attached to a glass substratum, i.e. similar to results obtained with Naegleria (King et al., 1982). At $2 \mathrm{~mm}-\mathrm{NaCl}$ or below, the adhesive force developed by the ventral surface of Acanthamoeba on glass was usually less than the force of gravity. However, with Naegleria we found (Davies et al., 1981) that even in distilled water the cell-substratum adhesive force was greater than the gravitational force acting on a locomoting amoeba. In Acanthamoeba the influence of gravity could well affect the efficiency of locomotion under low salt conditions.

The focal contacts detected by reflexion interference microscopy on the ventral surface of the amoeba in low ionic conditions remained fixed with respect to external co-ordinates. For movement on a substrate to occur traction must be developed. If the 'cytoskeleton' of each focal contact inserts into the viscous cortical tube (ectoplasm) traction can be developed. It is envisaged that the cortical tube is augmented at the front of the cell by actin polymerization and/or cross-linking and breaks down to a less viscous state at the back of the cell. The expansion and collapse of an actin network has been considered in detail for phagocytic leucocytes by Stossel (1982). For amoeboid locomotion to proceed it is important that adhesion (via focal contacts) and de-adhesion are carefully controlled. The formation of focal contacts occurs at the front edge of the platform or associated contact. If we assume that the anteriorposterior dimension of this rear platform is $10 \mu \mathrm{m}$, the speed of movement is $0.1 \mu \mathrm{m} \mathrm{s}^{-1}$, and the breakdown of focal contacts occurs at the rear margin of the platform, then one would predict the life expectancy of a single focal contact to be $10 / 0 \cdot 1=100 \mathrm{~s}$. This is much longer than the value of $16 \mathrm{~s}$ calculated for $N$. gruberi (King et al., $1983 \mathrm{~b}$ ) in $10 \mathrm{mM}-\mathrm{NaCl}$ at $20^{\circ} \mathrm{C}$, but it must be remembered that the speed of locomotion of $N$. gruberi is about ten times faster than that of $A$. castellanii.

Acanthopodia also remained fixed in relation to external co-ordinates yet did not anchor to the substratum. We therefore assume that the central bundle of actin filaments (Bowers \& Korn, 1968) within each of these projections must be inserted into the cortical tube which itself remains stable over the anterior two-thirds of the amoeba.

The biological significance of acanthopodia in the light of their lack of participation in traction on a planar substratum is puzzling. Their cyclic pattern of growth and dissolution seems so entrained with cell progression that some locomotory role in vivo cannot be fully discounted. It is possible that within the soil, acanthopodia might be able to exert traction by bracing Acanthamoeba to the walls of interstices of the soil while the lobopodium advances. Recent experiments have demonstrated the ability of Acanthamoeba to migrate through $5 \mu \mathrm{m}$ channels of Micropore filters (E. Urquhart, personal communication). Furthermore, post mortem examinations of victims of granulomatous amoebic encephalitis (Martinez, 1983) have borne 
testimony to the ability of this amoeba to move perfectly well within a three-dimensional matrix (substratum).

We wish to thank Mr L. G. Cooper for excellent technical assistance. This work was supported by a grant to T. M. P. from the SERC.

\section{REFERENCES}

BOWERS, B. \& KORN, E. D. (1968). The fine structure of Acanthamoeba castellanii I. The trophozoite. Journal of Cell Biology 39, 95-111.

Davies, A. M., Preston, T. M. \& King, C. A. (1981). Lack of gravity effect on the speed of amoeboid locomotion in Naegleria gruberi. Experientia 37, 708709.

King, C. A., Westwood, R., Cooper, L. \& Preston, T. M. (1979). Speed of locomotion of the soil amoeba Naegleria gruberi in media of different ionic compositions with special reference to interactions with the substratum. Protoplasma 99, 323-334.

King, C. A., DAvies, A. H. \& Preston, T. M. (1981). Lack of substrate specificity on the speed of amoeboid locomotion in Naegleria gruberi. Experientia 37, 709-710.

King, C. A., Preston, T. M., Miller, R. M. \& Grose, C. (1982). The cell surface in amoeboid locomotion studies on the role of cell-substrate adhesion. Cell Biology International Reports 6, 893-900.

KIng, C. A., Preston, T. M. \& Miller, R. M. $(1983 a)$. Cell-substrate interactions in amoeboid locomotion - a matched reflexion interference and transmission electron microscope study. Cell Biology International Reports 7, 641-649.

King, C. A., CoOper, L. G. \& Preston, T. M. (1983b). Cell-substrate interactions during amoeboid locomotion of Naegleria gruberi with special reference to alterations in temperature and electrolyte concentrations of the medium. Protoplasma 118, 10-18.

KoRN, E. D. (1963). Fatty acids of Acanthamoeba sp. Journal of Biological Chemistry 248, 439-447.

MARTINEz, A. J. (1983). Free living amoebae: pathogenic aspects. A review. Protozoological Abstracts 7 , 293-306.

Pollard, T. D., Aebi, V., Cooper, J. A., Fowler, W. E., Kiehart, D. P., SMith, P. R. \& TsENG, P. C. (1982). Actin and myosin function in Acanthamoeba. Philosophical Transactions of the Royal Society of London B299, 237-245.

Preston, T. M. \& KING, C. A. (1978a). Cell-substrate associations during the amoeboid locomotion of Naegleria. Journal of General Microbiology 104, 347351.

Preston, T. M. \& KING, C. A. (1978b). An experimental study of the interaction between the soil amoeba Naegleria gruberi and a glass substrate during amoeboid locomotion. Journal of Cell Science 34, 145-158.

Preston, T. M. \& O'Dell, D. A. (1980). The cell surface in amoeboid locomotion: behaviour of Naegleria gruberi on an adhesive lectin substrate. Journal of General Microbiology 116, 515-520.

Stossel, T. P. (1982). The structure of cortical cytoplasm. Philosophical Transactions of the Royal Society of London B299, 275-289. 